\title{
Fretting Wear of Rubber Sealing Ring Caused by Fluid Pressure Fluctuation
}

\author{
Yang HU*, Chuanjun HAN**, Jie ZHANG***, Zixuan LUO**** \\ *Southwest Petroleum University, Che ngdu, 610500,China, E-mail: lilylily_h@sina.com \\ **Southwest Petroleum University, Chengdu, 610500, China, E-mail: hanchuanjun@swpu.edu.cn \\ ***Southwest Petroleum University, Chengdu, 610500, China, E-mail: longmenshao@163.com \\ ****Sichuan Energy Internet Research Institute, Tsinghua University, Chengdu, 610042, China, \\ E-mail: luozixuan@tsinghua-eiri.org
}

crossref http://dx.doi.org/10.5755/j02.mech.28059

\section{Introduction}

As a one-time or refillable pressure vessel, the gas cylinder is often installed in the trunk of a car to store hydrogen, natural gas and other gas fuels. At the mouth of the gas cylinder, rubber sealing ring is usually installed to prevent the gas leakage. According to whether there is relative movement between the sealing ring and the cylinder line, the sealing is divided into two stages: the dynamic seal and the static seal. In the process of gas charging and discharging, the sealing ring is in the static seal but it isn't absolutely static. With the fluid pressure fluctuation, the sealing surface of sealing ring appears fretting causing fretting wear to lead the rubber chips and cracks. Due to the high viscoelasticity of rubber materials, fretting wear easily cause local rubber materials to be distortion, leading to seal failure. Hence, studying the fretting wear characteristics of the sealing ring is great significance to improve the safety and service life of the gas cylinder.

As the most important part to prevent gas leakage, the reliability of the sealing system directly determines the safety of gas cylinder. Dong et al. [1] studied the sealing performance of the fabric rubber under pressure difference and compressive displacement and analysed the gas leakage rate by the computational fluid dynamics method. Xuan et al. [2] found that the relationship of rubbing forces with rubbing time is the characteristic of abrasive wear of seal rubber. Ke et al. [3] established the friction model of the rubber seal to invest the kinetic friction characterizations and the stick-slip motion phenomena for rubber seals. Han et al. [4] studied the sealing performance of reciprocating O-ring seal during underwater operations to explore the sealing structure that facilitate the dynamic sealing performance. Pan et al. [5] developed an experimental apparatus to study the effects of seal diameter and sealing profiles on steady state friction force of hydraulic cylinders. Qiao et al. [6] considered the seal diameter and varying property to invest the sealing performance of transport and storage casks. The result showed the influence of seal diameter is negligible small. Zhou et al. [7-8] invested the fretting characteristic of a rubber seal in hydrogen atmosphere. And they found that the amplitude of reciprocating motion has a great influence on the fretting. Baek [9] studied the influence of temperature and surface roughness of the hard counterpart on the fretting characteristics of a rubber coating. These studies hardly focus on the fretting wear of the seal ring that caused by the fluid pressure fluctuation in the gas cylinder. Therefore, in this paper, the fretting wear of O-ring that installed at the gas cylinder mouth under the fluid pressure fluctuation is studied. Effects of compression ratio, friction coefficient and temperature field on the fretting wear is explored to improve the safety and service life of gas cylinder.

\section{Numerical model}

\subsection{Constitutive model of rubber}

Rubber is a highly elastic polymer material with reversible deformation. In the static seal, the initial assembly and compression ratio make the O-ring deforming to achieve self-sealing. According to the seal theory and the balance principle of force, the ratio of the maximum contact pressure on the sealing surface to the fluid pressure determines whether the sealing is successful. If the ratio is greater than 1, the sealing is achieved. Geometric nonlinearity, material nonlinearity and contact nonlinearity are three important characteristics of rubber materials. Therefore, it's essential to make the following assumptions before starting the study [10-12]:

1. The material has a certain elastic modulus and Poisson's ratio;

2. The tensile and compressive creep properties of the material are the same;

3. The transverse compression of the sealing ring is determined by the displacement of bound boundaries;

4. The volume of the sealing ring is not affected by material creep.

In this paper, the compression ratio of the sealing ring is $10-20 \%$. The Mooney-Rivlin is a constitutive model which can describe the deformation of rubber in $150 \%$. And it has great stability to express the rubber deformation in the small rage. Therefore, the Mooney-Rivlin is used to describe the fretting wear of the rubber sealing ring. The formula is as follows [13]:

$$
W=C_{1}\left(I_{1}-3\right)+C_{2}\left(I_{2}-3\right),
$$

where: $W$ is the strain energy density; $C_{1}$ and $C_{2}$ are Mooney-Rivlin coefficients and $I_{1}$ and $I_{2}$ are the first and second strain tensor invariant.

The relationship of stress and strain can be expressed as follows:

$$
\sigma=\partial W / \partial \varepsilon
$$




\subsection{Calculation model}

As the Fig.1, the two-dimensional axisymmetric model of the sealing system is established. The material of the cylinder liner and sealing groove is hard alloy steel. Poisson's ratio is 0.3 and the elastic modulus is $710 \mathrm{GPa}$. The diameter of the O-ring is $5.3 \mathrm{~mm}$. And the material of the O-ring is nitrile butadiene rubber (NBR), according to the rubber compression test, $C_{l}=1.79 \mathrm{MPa}, C_{2}=0.4 \mathrm{MPa}$ [14]. The penalty element method is used to simulate the interaction of the contact surfaces. The initial friction coefficient is 0.4. After the assembly is completed, the main seal surface (S.S.a), the secondary seal surface (S.S.b) and (S.S.c) are formed. The fluid pressure direction is shown in Fig.1. With the fluid pressure increases, the O-ring is squeezed out at $A$ area due to the limitation of the space.

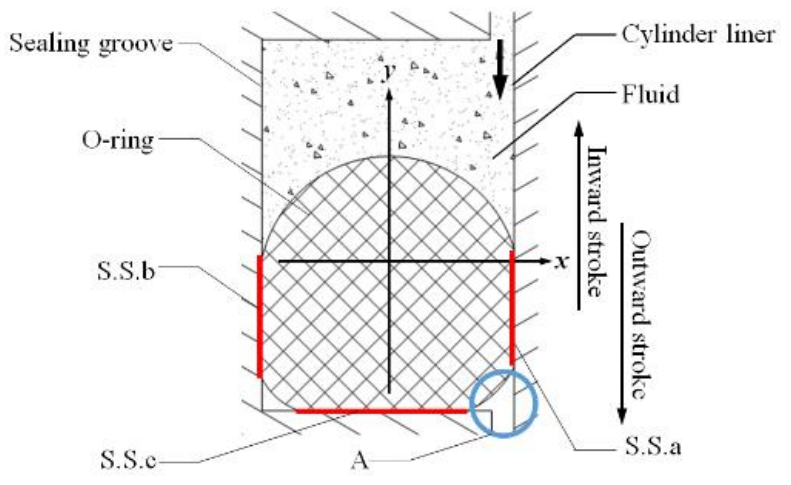

Fig. 1 Schematic diagram of O-ring structure

\section{Characteristics of fretting wear}

After completing self-sealing, the deformation of O-ring is aggravated under the working of the fluid pressure. And the fluid pressure fluctuates cause the fretting wear of sealing ring. And the shear stress is generated at the sealing surface. As shown in Fig. 2, according to the change of the shear stress, the fretting wear region of the sealing ring is divided into three regions with different characteristics: non-contact region, slip region and sticky region. In the noncontact region, the sealing ring doesn't contact with the metal surface (cylinder liner and sealing groove), so the shear stress is 0 . In the slip region, the sealing ring and the metal surface slip relatively. And the shear stress in this region changes monotonously. In the sticky region, the sealing ring and the metal surface are in a partial slip phase. The slip displacement is replenished by the elastic deformation of the rubber material. And the shear stress gradually decreases after reaching the maximum.
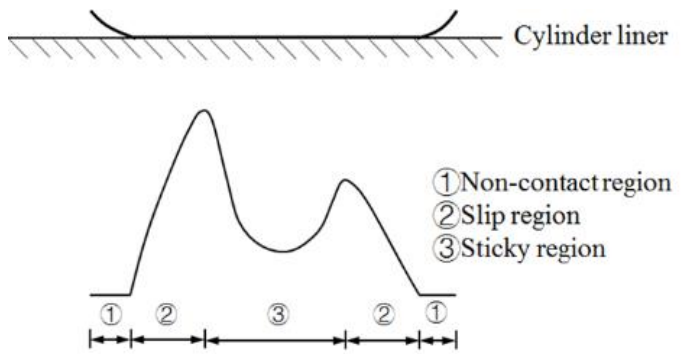

Fig. 2 The characteristic of fretting wear regions

When the fluid pressure is less than $10 \mathrm{MPa}$, the sealing ring is generally not equipped with a baffle. In this paper, the fretting wear changes of the main sealing surface
(S.S.a) that caused by fluctuates from $0 \mathrm{MPa}$ to $10 \mathrm{MPa}$ are studied. When the assembly is complete, there are only noncontact region and sticky region appear on the seal surface as shown in the Fig.3. And the direction of shear stress in the sticky region is the same. With the fluid pressure increases, a slip region appears on the S.S.a, and the length of the slip region increases. On the contrary, the length of the sticky region decreases. The left side of S.S.a is the side of fluid. The greater the fluid pressure, the longer the length of the non-contact region. Fretting wear in this area is mainly affected by fluid pressure. On the right side of S.S.a, the movable space of the sealing ring is limited. The sealing ring is deformed to the right under the working of fluid pressure. And the length of contact surface that in the right side increases. The greater the fluid pressure, the greater the shear stress. With the fluid pressure increases, the junction of the sticky region and slip region gradually moves to the right. The range of the sticky region decreases.

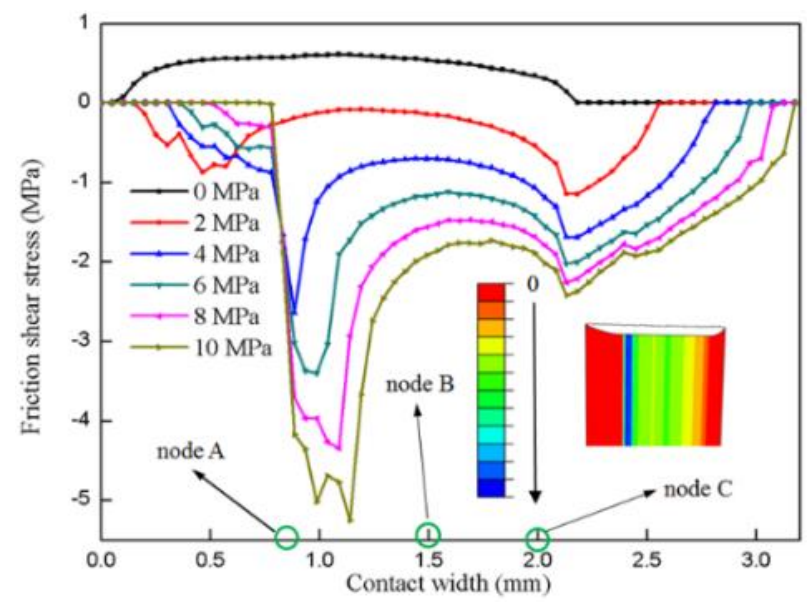

Fig. 3 Shear stress distribution of S.S.a under fluid pressures

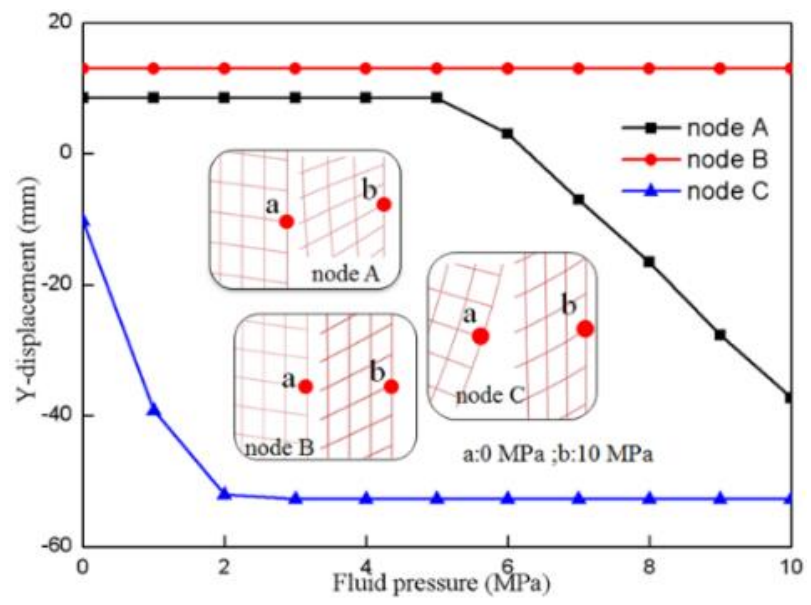

Fig. 4 Displacement of nodes under different fluid pressures

As shown in Fig .3, choosing three reference points (node $A$, node $B$, node $C$ ) to study the displacement change law in $0-10 \mathrm{MPa}$. The displacement curve on the $\mathrm{Y}$-axis and the schematic diagram of the movement of points are shown in Fig. 4. With the increasing of fluid pressure, node $B$ in the sticky region has no obvious change, and its displacement amplitude is replenished by rubber elastic deformation. The displacement changes of node $A$ and node $B$ is opposite. When the fluid pressure is greater than $5 \mathrm{MPa}$, node $\mathrm{A}$ in the left slip region obviously slip to the right. The greater the fluid pressure, the greater the displacement. When there is 
no fluid pressure, node $C$ is in the non-contact region. In the fluid pressure range of 0-2 $\mathrm{MPa}$, the node $C$ has obvious move. As the fluid pressure increases, the range of the slip region on the right side of node $C$ increases, and the displacement of node $C$ decreases. The reason to explain this phenomenon is that the left slip region where node $A$ is located is more affected by fluid pressure and the right slip region where node $C$ is located is more affected by space.

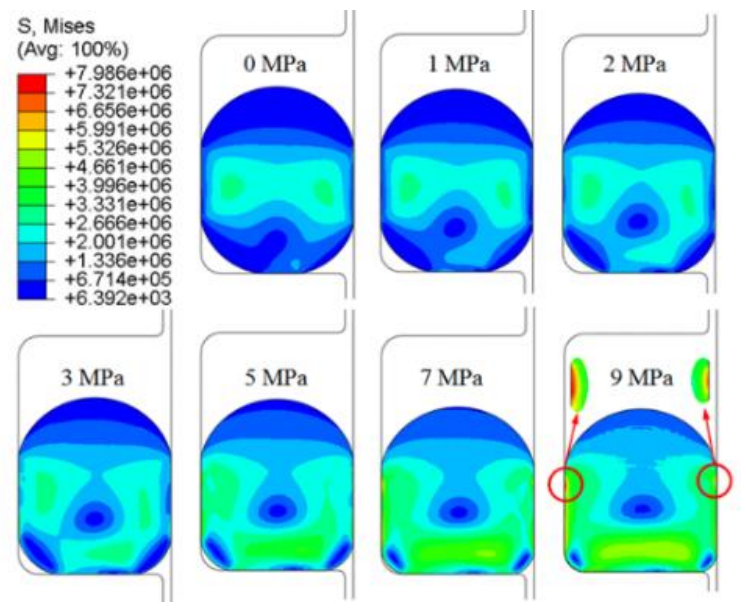

Fig. 5 Stress distribution under different fluid pressures

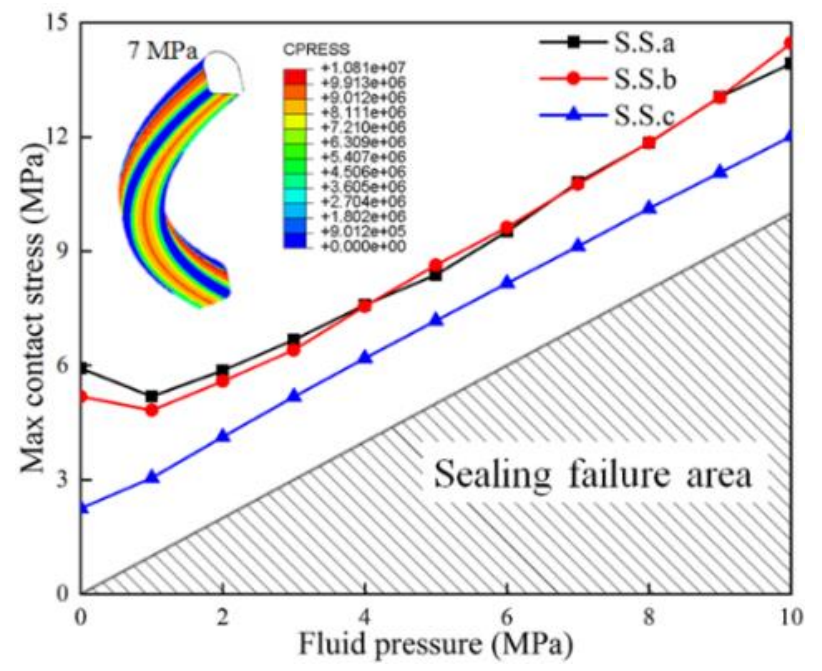

Fig. 6 Contact pressure under different fluid pressures

Fig. 5 shows the von-Mises stress distribution of O-ring under different fluid pressures. With the fluid pressure increases, a low-stress area appears inside the crosssection of the sealing ring. The shape of the high-stress area changes from a dumbbell shape to a U shape when the assembly is completed. And the number of high-stress area increases from 2 to 3 . When the influence of fluid pressure on stress is greater than that of the assembly, a U-shaped highstress area is formed, the stress concentrate in the slip region of S.S.a and S.S.b where near the fluid. And this area is most prone to seal failure. In Fig. 6, the contact pressure of S.S.a and S.S.b is greater than S.S.c after the assembly. The direction of fluid pressure is perpendicular to the direction of contact pressure on the S.S.a and S.S.b. Within 0-10 MPa, the maximum contact pressure on S.S.a and S.S.b first decreases and then increases. When the fluid pressure is $1 \mathrm{MPa}$, the contact pressure is the smallest. The direction of fluid pressure is the same as the direction of contact pressure on S.S.c. The contact pressure increases with the increasing of fluid pressure.

\section{Sensitivity factors}

\subsection{Compression ratio}

Taking the perimeter of the cross-section of the Oring as the research path, the contact pressure distribution of the path under different compression ratios is shown in Fig. 7. In the compression ratio of $10-18 \%$, the maximum contact pressure on the sealing surface is greater than the fluid pressure. So the compression ratio of $10-18 \%$ doesn't affect the safety work of the sealing system. With the increasing of compression ratio, the contact pressure of the S.S.a and S.S.b gradually increases. And the contact pressure fluctuations appear on the sealing surface. The rubber material and the metal surface are displaced in the slip region of S.S.a and S.S.b. Under the influence of compression ratio and fluid pressure, the maximum contact pressure is less than the fluid pressure. In the sticky region, the rubber material and the metal surface are sticky and have a relative movement tendency. In order to prevent relative movement, the maximum contact pressure in the sticky region will fluctuate. Therefore, the compression ratio has a greater impact on the sealing performance of sticky region of S.S.a and S.S.b. but the S.S.c is less.

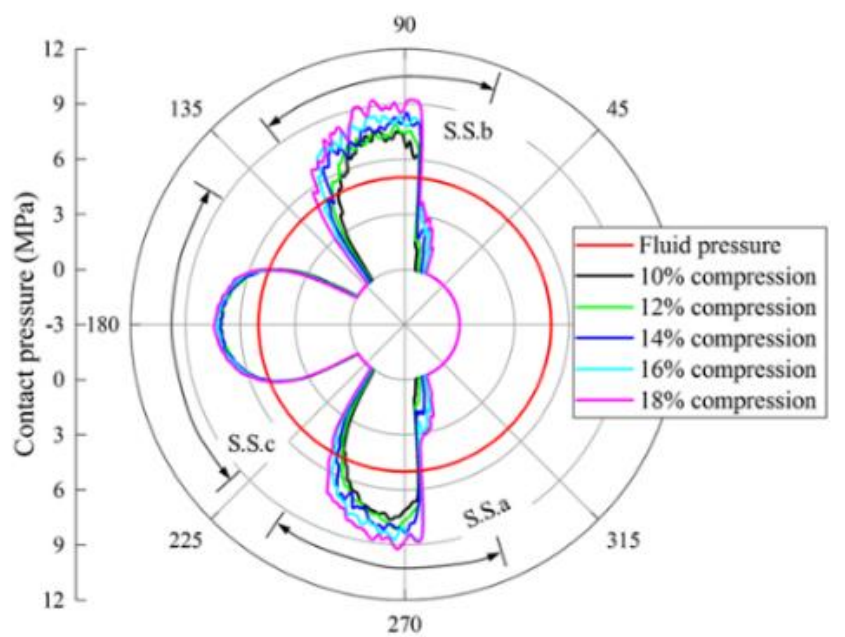

Fig. 7 Contact pressure curves under compression ratios

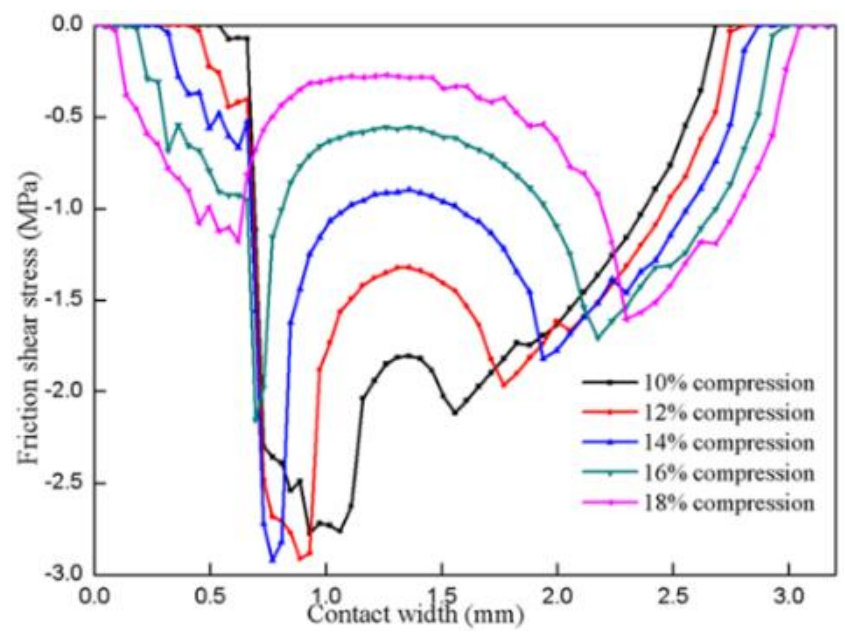

Fig. 8Shear stress curves under different compression ratios

In Fig. 8, with the increasing of the compression ratio, the length of S.S.a is extended, the range of the sticky region is enlarged, and the non-contact region is reduced. In 
the range of $10-14 \%$ compression ratio, the maximum tangential force $(F t)$ on the sealing surface is greater than the limit friction $(T=\mu P)$. The tangential force is mainly affected by the fluid pressure. When the compression ratio exceeds $14 \%$, the deformation of O-ring intensifies and the contact pressure of S.S.a increases, and the shear stress of S.S.a decreases with the increasing of the compression ratio.

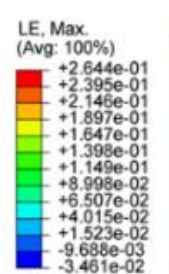

Compression S. Mises
(Avg: $100 \%$ )

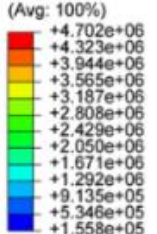

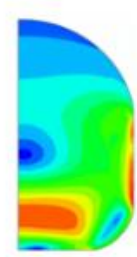

$10 \%$

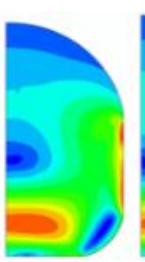

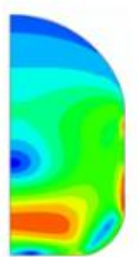

$12 \%$

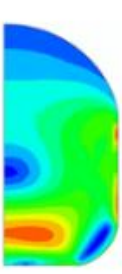

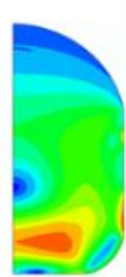

$14 \%$

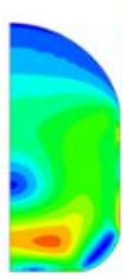

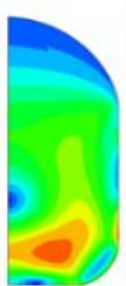

$16 \%$

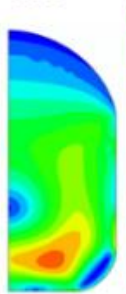

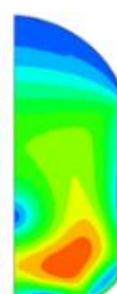
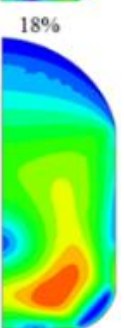

Fig. 9 Stress-strain distribution under compression ratios

Using the stress-strain of material to reflect the degree of material failure. The logarithmic strain (LE) distribution and stress distribution of the O-ring under different compression ratios is shown in Fig. 9. The distribution of stress-strain in the cross-section of the O-ring are similar. A low stress-strain area appears in the center of the cross section, but a high stress-strain area appears below. As the compression ratio increases, the low stress-strain area decreases, and the high stress-strain area moves to both sides. When the compression ratio is small, the distribution of stressstrain on the sealing surface is mainly affected by the fluid pressure. Stress-strain around the sealing surface are concentrated on the sticky region. Rubber chips and cracks are easy to be produced in this region leading to seal failure. Therefore, a reasonable compression ratio can ensure the sealing performance and prolong the service life of the sealing system.

\subsection{Friction coefficient}

When the compression ratio is $14 \%$ and the fluid pressure is $5 \mathrm{MPa}$, the fretting wear characteristics of the $\mathrm{O}$ ring with 0.1-0.4 friction coefficient are analysed. In Fig. 10, the friction coefficient doesn't affect the sealing performance of the seal system. The contact pressure of S.S.a and S.S.b fluctuates. The greater the friction coefficient, the smaller the degree of contact pressure fluctuation. The maximum contact pressure occurs in the sticky region near the fluid. The contact pressure of S.S.c has no obvious fluctuations. When the friction coefficient is 0.1 , the contact pressure is the largest. When the friction coefficient is in the range of $0.2-0.4$, the difference in the average contact pressure is small, and the distribution of maximum contact pressure on the sealing surface is symmetrical. In the static seal, the O-ring has no relative movement, and the S.S.a and S.S.b are more affected by the fluid pressure fluctuation. The greater the friction coefficient, the greater the force that prevent the fretting wear.

Fig.11 shows the length of the non-contact region on both sides of the S.S.a has no significant change. The friction coefficient has little effect on the non-contact region. When the $f<0.2$, the friction force is small, and there is no sticky region in the S.S.a. Under the influence of fluid pressure, fretting wear is easy to occur. When the $f>0.2$, the non-contact region, slip region and sticky region co-exist in the S.S.a. The greater the friction coefficient, the greater the shear stress at the junction of the slip region and sticky region The smaller the shear stress in the sticky region, but the greater the shear stress difference. Under different friction coefficients, the logarithmic strain (LE) distribution and stress distribution of the O-ring is shown in Fig. 12. As the friction coefficient increases, a low stress-strain area is appeared inside the cross-section. And a high stress-strain area appears at the junction of the sticky region and the slip region. Friction coefficient is the main factor affecting the distribution of sticky region and the slip region. The fretting wear can be reduced by a higher friction coefficient.

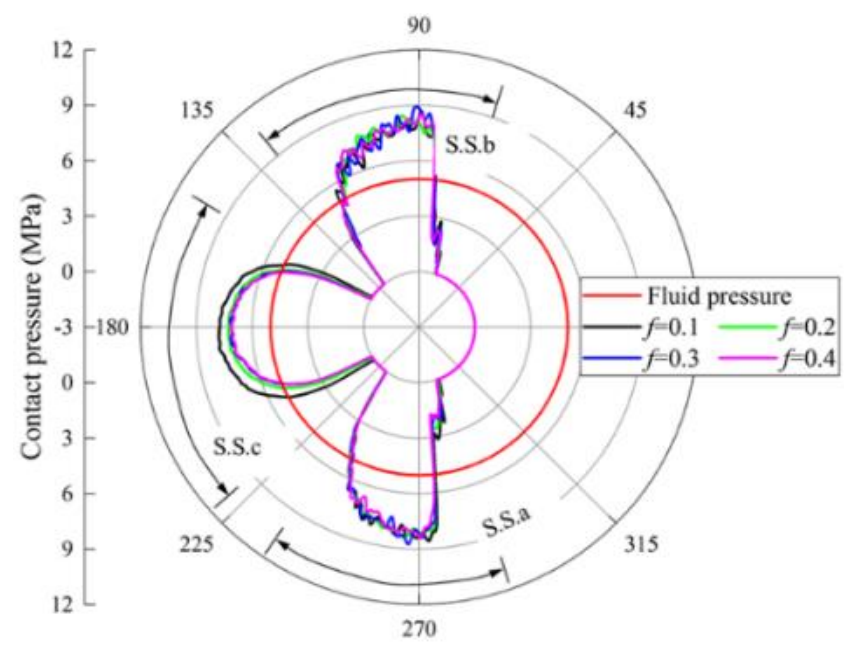

Fig. 10 Contact pressure curves under friction coefficients

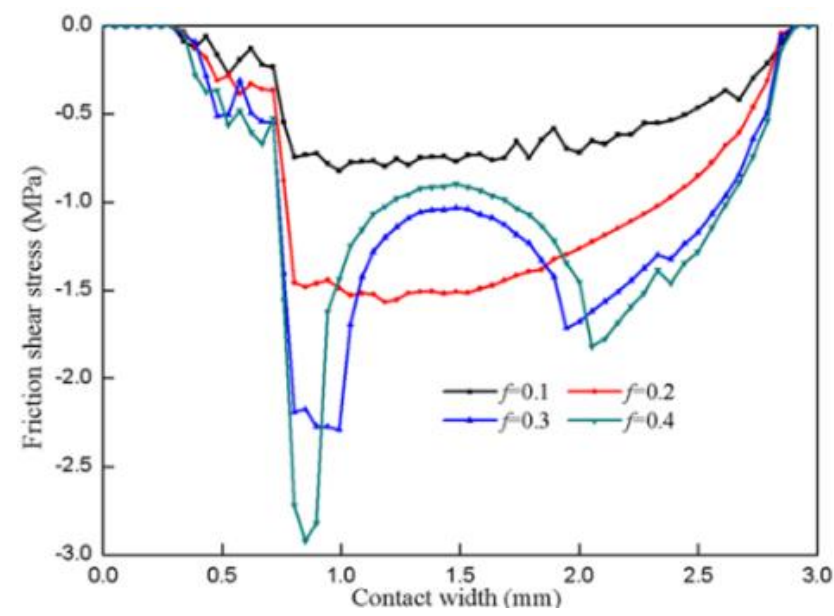

Fig. 11 Shear stress curves under friction coefficients

\subsection{Temperature field}

Thermal expansion of the rubber caused by ultrahigh working temperature field changes the stress-strain of the O-ring. Nitrile butadiene rubber (NBR) is the material to make O-ring. The working temperature field of O-ring doesn't exceed $120^{\circ} \mathrm{C}$. As shown in the Fig. 13, the contact pressure of sealing surface increase with the working temperature rises. Under the influence of the temperature field, the thermal expansion of the rubber causes the length of 
S.S.a and S.S.b to increase. The length of the main sealing surface (S.S.a) increases by $9.4 \%$. In the $0-120^{\circ} \mathrm{C}$ temperature field, the maximum contact pressure is $9.259 \mathrm{MPa}$. Compared with no temperature field, the maximum contact pressure increases by $6.22 \%$. In this paper, the thermal expansion caused by the temperature field has little effect on the sealing performance of the sealing ring.

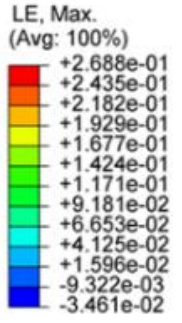

Friction coefficient $\quad 0.1$ $\mathrm{S}$, Mises (Avg: 100\%) $+5.039 \mathrm{e}+06$ $+4.633 \mathrm{e}+06$ $+4.228 \mathrm{e}+06$ $+3.823 \mathrm{e}+06$
$+3.418 \mathrm{e}+06$
$+3.012++06$ $+3.418 \mathrm{e}+06$
$+3.012 \mathrm{e}+06$ \begin{tabular}{l}
$+3.012 \mathrm{e}+06$ \\
$+2.607 \mathrm{e}+06$ \\
\hline
\end{tabular} $+2.202 \mathrm{e}+06$ $+1.797 \mathrm{e}+06$ $1.391 \mathrm{e}+06$ $+9.861 \mathrm{e}+05$ $+5.808 \mathrm{e}+05$
$+1.755 \mathrm{e}+05$
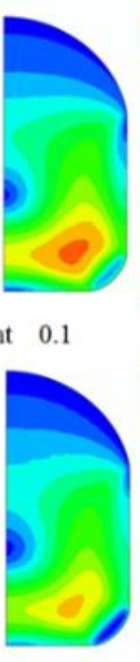

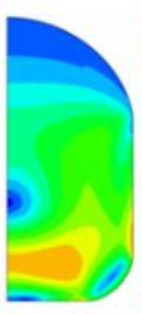

0.2

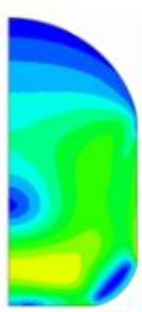

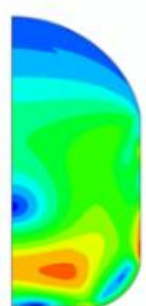

0.3

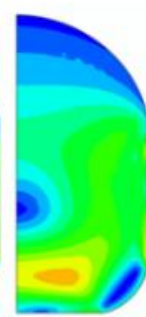

Fig. 12 Stress-strain distribution under friction coefficients

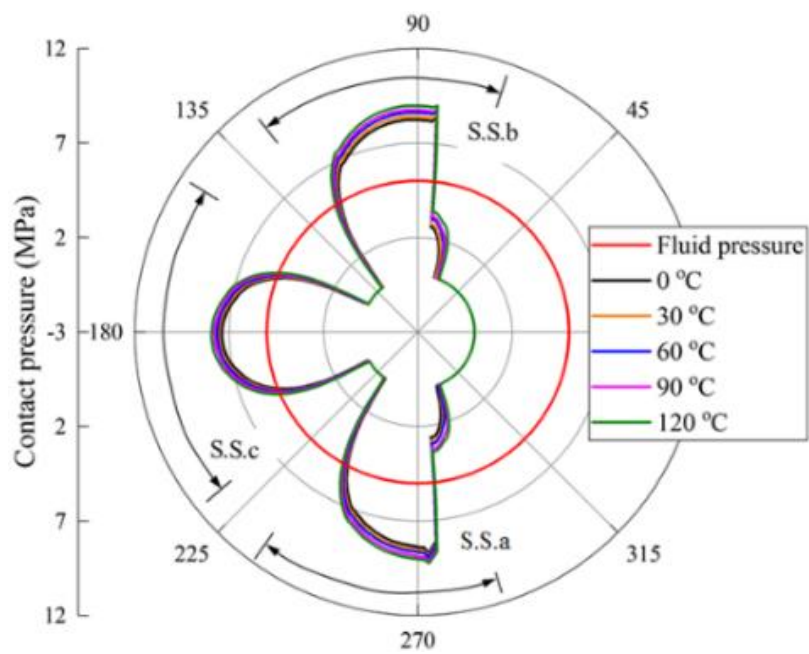

Fig. 13 Contact pressure curves under temperatures

In Fig. 14, under different temperature fields, noncontact region, slip region, and sticky region all appear on the S.S.a. After the thermal expansion happened, the volume of rubber gradually increases. On the side near the fluid, as the temperature irises, the shear stress will increase. In this region, the temperature field has a great influence on fretting wear. After the shear stress reaches the maximum value, it gradually decreases to zero. The direction of shear stress changes to be opposite. And then under the influence of the fluid pressure, the shear stress increases. At the junction of the slip region and sticky region, the shear stress reaches the peak. As shown in Fig. 15, with the increasing of the temperature field, the low stress-strain area shrinks, and the high stress-strain area expands. The stress of the S.S.a near the fluid gradually decreases with the increasing of the temperature field. Therefore, high temperature field can relieve the local stress concentration. But thermal expansion expands the high stress-strain area, which is prone to rubber cracks causing seal failure.

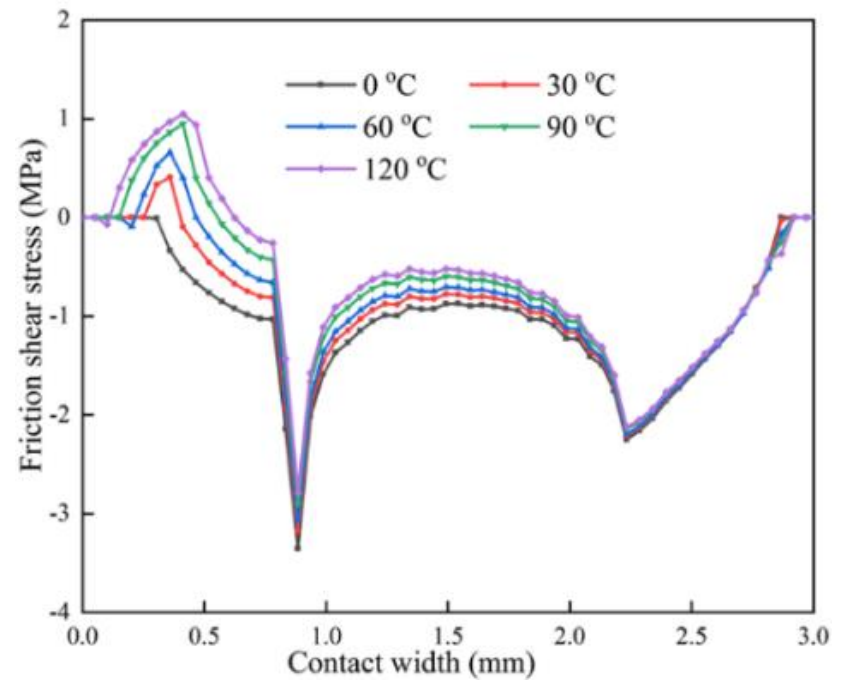

Fig. 14 Shear stress curves under different temperatures
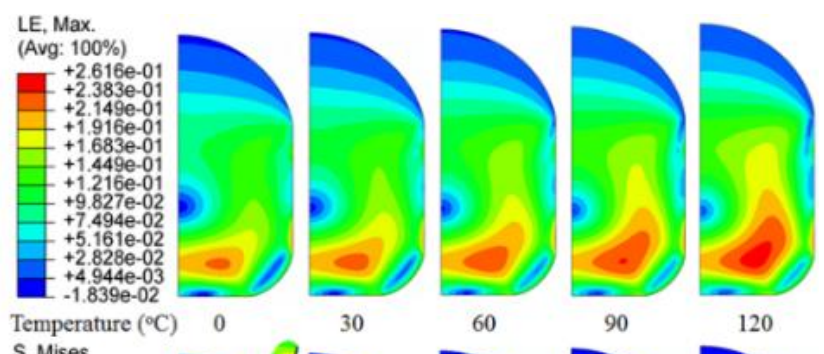

S, Mises

30

60

120

(Avg: $100 \%$ )

$+4.350 \mathrm{e}+06$
$-+3.993 \mathrm{e}+06$
$+3.635 \mathrm{e}+06$

$+3.635 \mathrm{e}+06$
$+3.278 \mathrm{e}+06$

$+2.921 \mathrm{e}+06$
$+2.563 \mathrm{e}+06$

$++2.206 \mathrm{e}+06$

$+1.849 \mathrm{e}+06$

$+1.491 \mathrm{e}+06$
$+1.134 \mathrm{e}+06$
$+7.763 \mathrm{e}+05$

$+4.190 \mathrm{e}+05$
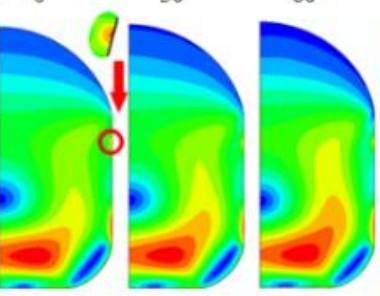

90

120

Fig. 15 Stress-strain distribution under temperatures

\section{Conclusion}

1. In the static seal, the fretting wear on the sealing surface that caused by fluid pressure fluctuation can be divided into non-contact region, slip region and sticky region. The greater the fluid pressure, the more severe the fretting wear. The stress-strain are concentrated at the junction of slip region and sticky region. After long-term working, it is easy to cause seal failure in this region.

2. With the increasing of compression ratio, the sticky region expands. The sealing performance of sealing structure is great. When the $f<0.2$, there are only non-contact region and slip region, and fretting wear is easy to occur. The temperature field has little effect on the sealing performance of the sealing system. But rubber thermal expansion caused by ultra-high temperature results in a high stressstrain area in the cross-section of the O-ring, which is prone to rubber chips and cracks.

\section{Acknowledgments}

This work was supported by Sichuan outstanding youth fund program (19JCQN0081). 


\section{References}

1. Dong, Y.F.; Ke, Y. Z.; Zheng, Z. 2017. Effect of stress relaxation on sealing performance of the fabric rubber seal, Composites Science and Technology 151(20): 2991-301. https://doi.org/10.1016/j.compscitech.2017.08.025.

2. Xuan, H. J.; Zhang, N.; Lu, B. 2017. Investigation of high-speed abrasion behavior of an abradable seal rubber in aero-engine fan application, Chinese Journal of Aeronautics 30(4): 11615-1623. https://doi.org/10.1016/j.cja.2017.02.019.

3. Ke, Y. C.; Yao, X. F.; Yang, H.; Liu, X. Y. 2014. Kinetic friction characterizations of the tubular rubber seals, Tribology International 72: 35-41. https://doi.org/10.1016/j.triboint.2013.12.004.

4. Han, Q.; Chen, H. Y.; Yang, W. C. 2019. Analysis of reciprocating O-ring seal in the pressure-balanced oilfilled wet-mate electrical connectors for underwater applications, Lubrication Science 31(7): 335-345. https://doi.org/10.1002/ls.1475.

5. Pan, Q.; Zeng, Y. L.; Li, Y. B. 2021. Experimental investigation of friction behaviors for double-acting hydraulic actuators with different reciprocating seals, Tribology International 153: 106506. https://doi.org/10.1016/j.triboint.2020.106506.

6. Qiao, L. N.; Keller, C.; Zencker, U. 2019. Three-dimensional finite element analysis of O-ring metal seals considering varying material properties and different seal diameters, International Journal of Pressure Vessels and Piping 176:103953.

https://doi.org/10.1016/j.ijpvp.2019.103953.

7. Zhou, C. L.; Chen, G. H.; Xiao, S. 2019. Study on fretting behavior of rubber O-ring seal in high-pressure gaseous hydrogen, International Journal of Hydrogen Energy 44(40): 22569-22575. https://doi.org/10.1016/j.ijhydene.2019.02.224.

8. Zhou, C. L. 2015. Research on material mechanics properties testing equipment in $140 \mathrm{MPa}$ high-pressure hydrogen environment, Zhe Jiang University. (in Chinese)

9. Baek, D. K.; Khonsari, M. M. 2008. Fretting behavior of a rubber coating: Effect of temperature and surface roughness variations, Wear. 265(5): 620-625. https://doi.org/10.1016/j.wear.2007.12.002.

10. Fired, I.; Johonson, A. R. 1988. Nonlinear computation of axisymmetric solid rubber deformation, Computer Methods in Applied Mechanics and Engineering 67: 241-253. https://doi.org/10.1016/0045-7825(88)90128-4.

11. Dragoni, E.; Strozzi, A. 1988. Analysis of an unpressurized, laterally restrained, elastomeric O-ring seal, Journal of Tribology 110(2): 193-200.

https://doi.org/10.1115/1.3261583.

12. Warren, W.E.; Curro, J. G.; Amos, D.E. 1988. On the nature of O-rings in contact with rough surfaces, Journal of Tribology 110(4): 632-637. https://doi.org/10.1115/1.3261705.

13. Zhang, J.; Xie, J. X. 2018. Investigation of static and dynamic seal performances of a rubber O-ring, Journal of Tribology 140(4): 042202. https://doi.org/10.1115/1.4038959.

14. Zhang, J.; Hu, Y. 2019. Mechanical behavior and sealing performance of metal sealing system in roller cone bits, Journal of Mechanical Science and Technology 33(6): 2855-2862.

https://doi.org/10.1007/s12206-019-0533-5.

Y. Hu, Ch. Han, J. Zhang, Z. Luo

FRETTING WEAR OF RUBBER SEALING RING CAUSED BY FLUID PRESSURE FLUCTUATION

S u m m a r y

In the process of gas charging and discharging of gas cylinder, the fluid pressure fluctuates causing fretting wear of rubber sealing ring, which affects the sealing performance. The model of O-ring that installed at the mouth of the gas cylinder was established to study the fretting wear in the static seal. Effects of fluid pressure, compression ratio, friction coefficient and temperature on the fretting wear of the O-ring were considered. The results show that the fretting wear of O-ring can be divided into non-contact region, slip region and sticky region. In the static seal, the compression ratio and friction coefficient are the main factors affecting the fretting wear. The sealing performance is greatly influenced on the compression ratio and it is less affected by the temperature. The junction of slip region and sticky region has the greatest probability of seal failure.

Keywords: fretting wear, fluid pressure fluctuation, rubber sealing ring, stress-strain, sealing performance.

Received November 23, 2020 Accepted August 07, 2021 